\title{
Reality and confusion in the recognition of post- depositional alterations and use-wear: an experimental approach on basalt tools
}

\author{
Lena Asryan 1,2,3, Andreu Ollé ${ }^{2,1}$ and Norah Moloney ${ }^{4}$ \\ 1. Àrea de Prehistòria, Universitat Rovira i Virgili (URV). Avinguda de Catalunya 35, 43002 Tarragona, Spain. \\ Email: lenaprehistoria@gmail.com \\ 2. IPHES, Institut Català de Paleoecologia Humana i Evolució Social. C/Marcel.lí Domingo s/n (Edifici W3), \\ Campus Sescelades, 43007, Tarragona, Spain. Email: aolle@iphes.cat \\ 3. Artsakh State University. M. Gosh 5, Stepanakert, Nagorno Karabagh. \\ 4. University College London, Institute of Archaeology, 31-34 Gordon Square, London WH1E OPY, UK. \\ Email: tcfa305@ucl.ac.uk
}

\begin{abstract}
:
While many experimental studies have been done on siliceous and metamorphic rocks for both use-wear and post depositional surface modification (PDSM) events, little is known about such experiments on volcanic materials (other than obsidian), and on basalt in particular. Here we present the preliminary results of several experiments related to: a) evidence for basalt use (e.g., butchery and fresh hide scraping) and the subsequent characteristic use-wear patterns that can be seen; and b) postdepositional surface modifications caused by bear (Ursidae) trampling on experimental basalt flakes and subsequent use of these flakes for a tumbling experiment in a special tumbling machine.

The results of these experiments were compared to better understand some surface modifications noted on the Middle to Upper Pleistocene lithic assemblages of the Azokh Cave site (Nagorno Karabagh, Lesser Caucasus).

Although some aspects of both events (use-wear and PDSM) remain to be studied in depth, the experiments have improved our understanding of the effects of use-wear and post-depositional trampling and tumbling on basalt lithic artefacts. In particular, it has allowed us to recognise mechanical alterations (e.g., cracks, striations, fractures, edge damage) caused by trampling and tumbling and to note differences between these modifications and those caused by use. In particular, the experiments have shown that macroscopic modifications are rarely diagnostic, especially those observed after use. Microscopic wear features such as edge rounding, polish, abrasion and striations were the most evident types of alteration on basalt flakes, although occurring at different times and from different types of use. Distribution and orientation of alterations may be key in distinguishing use-wear from post-depositional alterations on basalt artefacts.
\end{abstract}

Keywords: experimental case-studies; basalt; use-wear patterns; post-depositional surface modifications (PDSM)

Published by the School of History, Classics and Archaeology, University of Edinburgh ISSN: 2055-0472. URL: http://journals.ed.ac.uk/lithicstudies/

This work is licensed under a Creative Commons Attribution 2.5 UK: Scotland License. 


\section{Introduction and background}

Diverse experiments related to the functional patterns of different experimental stone tools made of various sedimentary (e.g., chert and flint), metamorphic (quartzite in particular) rocks, as well as quartz, have been made (among many others, see for example, Tringham et al. 1974; Odell 1977; Toll 1978; Hayden 1979; Kamminga 1979; Keeley 1980; Vaughan 1985; Knutsson 1986; Sussman 1988; Grace 1989; Clemente \& Gibaja 2009). The types of alteration evident on these rocks after use for different actions (e.g., cutting, scraping, chopping, sawing) and on different materials (e.g., meat, wood, hide, bone) is well described. Although with some differences, most authors describe polish, edge rounding, striations, abrasions and edge damage as the most common use-wear features seen.

Experiments related to the study of post-depositional surface modifications (PDSM) on experimental tools of various rocks (in particular chert, flint, quartzite and quartz) have also been the subject of various studies (Newcomer 1976; Flenniken \& Haggarty 1979; Levi-Sala 1986; Van Gijn 1990; McBrearty et al. 1998; Vallin et al. 2001; Burroni et al. 2002; Thiébaut 2007). Such alterations as sheen formation, edge damage, cracks, fractures, striations, deformations, edge and ridge rounding, polished surfaces, pits and surface colour changes have been classified as the most common PDSM types. Questions about the differences between PDSM alterations, use-wear and just technical alterations (retouch) of archaeological stone tool artefacts have also been addressed by some authors.

However, similar experiments and comparisons of functional and post- depositional alterations have not been as well explored or developed for lithic artefacts on volcanic materials. Most commonly, obsidian has been used for use-wear experiments (Hurcombe 1992; Barton et al. 1998; Araho et al. 2002; Hong \& Kononenko 2005; Kononenko 2007; Beyin 2010; Kononenko 2011) although less so for PDSM experiments. A few authors have addressed functional and micro-wear analyses on basalt or basaltic rocks (Plisson 1982; Richards 1988; Deunert 1995; Rodríguez Rodríguez 1998; Clemente \& Gibaja 2009) but little experimental work has been published.

Because of the limitations of the study and characterisation of use-wear and postdepositional alterations on basalt tools, as well as some types of alteration (post-depositional and perhaps also functional) seen on archaeological basalt lithics at the Middle Pleistocene site of Azokh Cave (Nagorno Karabagh), we designed experimental studies related to basalt use and formation of PDSM. We should emphasise that our experiments are at an initial stage and our results are preliminary. However observations noted so far during these experiments will allow ongoing studies to continue and aid our understanding of basalt and of the alterations observed on the archaeological material of Azokh Cave.

The aim of this preliminary study was: 1) to reproduce and to characterise use-wear patterns from butchery and fresh hide scraping; 2) to explore experimentally the possibility of bear (Ursidae) trampling and water-induced tumbling as possible PDSM agents on tools; 3) to assess possible coincidences among traces left on experimental tools; and 4) in terms of possibilities, compare the results with the archaeological artefacts of Azokh Cave. We chose these specific actions, and trampling and tumbling agents as a way of exploring and following

phenomenon already observed in the archaeological record. Bears (Ursidae) were chosen for the trampling experiment as this is the dominant species within the faunal assemblages of Azokh Cave (van der Made et al. (in press)). The tumbling experiment was chosen in order to address our doubts about the origins of some of the PDSM observed on the archaeological materials of the cave (e.g., heavy rounding, unevenly distributed striations, edge damage, etc.) (Asryan et al. (in press); Marín-Monfort et al. (in press)).

These experiments are important in order to identify specific types of use-wear patterns on basalt and to understand how they differ from those on other rocks; to determine the type 
of alteration that bear trampling and other PDSM agents can produce on the surface of basalt artefacts (e.g., edge damage, micro-fractures, rounding, striations, etc.); and finally, to establish criteria to distinguish this PDSM from use-wear traces on basalt.

\section{Material and methods}

Our experiments were sequential in character, but not all have been completed yet, and some are ongoing. Although they were clearly designed for both use-wear and PDSM events, we used a limited number of experimental pieces in order to better control and study all artefacts and processes and to undertake macroscopic and microscopic analyses of each piece. We studied the experimental pieces at three different stages or times of use (explained fully below). The sequential character of our experiments is an important factor as it allows us to see and compare the same area or the same point of the flake at different stages or after different times of use, therefore enabling us to see all gradual changes that occurred in the area of interest (Ollé \& Vergès (in press)).

Two sets (thirty in total) of experimental flakes of different raw materials were prepared. Functional experiments covered the sequential use of experimental, unretouched basalt flakes for two activities that would have been undertaken in prehistory: skinning and scraping of fresh hide. The time sequences monitored were: time $0=$ unused piece, time $1=20$ minutes of use, time $2=30$ minutes of use, which together gave a total of 50 minutes of use. The PDSM experiments included the trampling by bears (Ursidae) of a set of flakes in the first stage which then continued in a second stage in a tumbling machine (time $0=$ initial stage, time $1=3$ months of trampling; time $2=20$ hours of tumbling). In this paper we present the preliminary results of our initial observations of the basalt pieces. Experiments and observations are ongoing and new results and comparisons will be available soon. Depending on the results of the entire experimental assemblage, adjustments will be introduced and this methodology will be applied to a larger number of pieces.

\subsection{The experiments}

\subsubsection{Raw material and flake production}

Fine-grained, homogenous, high quality olivine basalt cobbles were collected from fluvial deposits near Azokh Cave. One block (Ishbas1) was knapped by an expert knapper using direct percussion with a quartzite hammerstone. We chose to use flakes suitable for both functional and PDSM experiments ranging between 4.5 and $9 \mathrm{~cm}$ (Table 1).

Table 1. Experimental pieces and method of use in the experiments. Abbreviations: bt - bear trampling; $\mathrm{t}$ - tumbling.

\begin{tabular}{|c|c|c|c|c|c|}
\hline $\begin{array}{l}\text { Experimental } \\
\text { pieces }\end{array}$ & Experiments & & $\begin{array}{c}\text { Edge or surface } \\
\text { involved }\end{array}$ & Action & $\begin{array}{l}\text { Total time of } \\
\text { experiment }\end{array}$ \\
\hline & time 1 & time 2 & & & \\
\hline Ishbas1-MC1 & deer skinning & $\begin{array}{l}\text { wild boar } \\
\text { skinning }\end{array}$ & distal end & $\begin{array}{l}\text { Longitudinal- } \\
\text { unidirectional }\end{array}$ & $50 \mathrm{~min}$ \\
\hline Ishbas1-HS1 & $\begin{array}{l}\text { scraping of deer } \\
\text { fresh hide }\end{array}$ & $\begin{array}{l}\text { scraping of wild } \\
\text { boar fresh hide }\end{array}$ & left lateral & $\begin{array}{c}\text { Transversal- } \\
\text { unidirectional }\end{array}$ & $50 \mathrm{~min}$ \\
\hline Ishbas 1 & bt & $\mathrm{t}$ & whole surface & -- & 3 months $(b t) \& 20 h(t)$ \\
\hline Ishbas2 & bt & $\mathrm{t}$ & whole surface & -- & 1 day $(\mathrm{bt}) \& 20 \mathrm{~h}(\mathrm{t})$ \\
\hline
\end{tabular}


The experimental pieces were measured, photographed and cleaned individually, in an ultrasound cleaning bath with a $2 \%$ solution of buffered soap (Derquim) for ten minutes and then with industrial pure $(99,9 \%)$ acetone for another five minutes in order to remove any recent residues (e.g., finger fat, particles resulting from knapping, dust, human skin residues) that had accumulated on the pieces. Moulds were prepared using Provil Novo silicone (base and light pastes) always including the edge or edges of interest and part of the dorsal or ventral ridges. Positives of the moulds or the casts were prepared using a rigid polyurethane resin Feropur PR-55 (Synthesia Española S.A). Casts provide an exact copy of the initial stage of experimental pieces to facilitate later comparison with the post-experimental pieces.

\subsubsection{Use-wear experiments: skinning and scraping with basalt flakes}

The first stage of the use-wear experiments included skinning a deer (Cervus elaphus) and scraping fresh hide for 20 minutes. Deer butchery and hide scraping experiments were undertaken at the Boumort National Hunting reserve area (Lleida, Spain), where each spring 2-3 deer (Cervus elaphus), shot by forest rangers to control deer population, are offered to researchers for experimental or scientific purposes. In the second stage of the experiment, the same experimental pieces were used for 30 minutes to skin a wild boar (Sus scrofa) (hunted in the forests of Alcover, Tarragona, Spain) and afterwards to scrape its fresh hide.

A left-handed archaeologist, experienced in butchery, used a flake (Ishbas1-MC1) to skin an adult deer of 60-65 kg (Figure 1) for 20 minutes (630 strokes) using the flake's distal end (in particular the left side of the edge which has a convex profile and an edge angle of $15^{\circ}$ ) always with longitudinal-unidirectional movements and a high working angle $\left(75-90^{\circ}\right)$. During the process, although both dorsal and ventral faces were in contact with the skin and sometimes the meat and bones (especially the leg area), the ventral face was in constant contact with all these areas. In time 2, the same piece was used to skin the wild boar (Figure 1) for almost 30 minutes, once again using the distal end of the piece (and its left side in particular) in longitudinal-unidirectional actions. After each experiment the piece was washed in clean water and wrapped in soft tissue to avoid damage from extraneous sources during transportation to the laboratory.
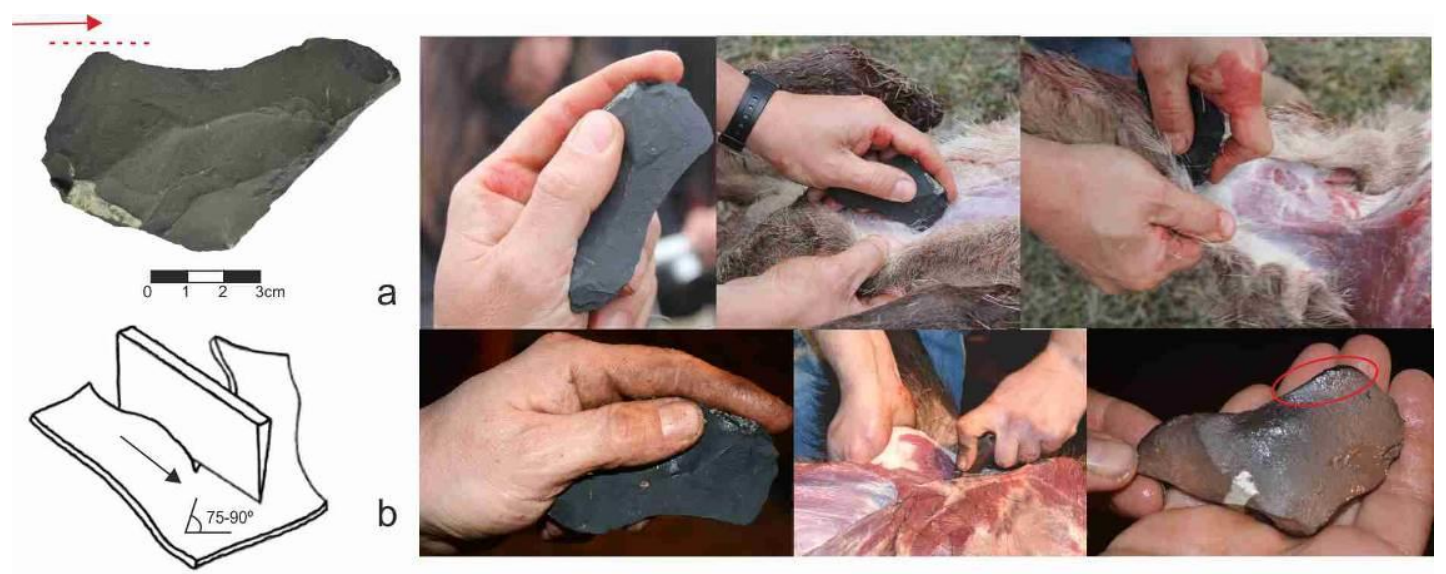

Figure 1. Ishbas1-MC1flake used for skinning: a) time 1 - deer skinning; b) time 2 - wild boar skinning. Dashed line on the edge indicates the most active area of edge used during the experiment. Arrow indicates direction of tool movement. The illustration below shows direction of movement and the working angle.

A second basalt flake (Ishbas1-HS1) was used in time 1 to scrape a fresh deer-hide which retained some meat and fat tissue (Figure 2). The hide was placed hair-side down on the ground of the reserve area. The active edge of this piece was a straight left lateral, high angled $\left(70-75^{\circ}\right)$ edge. The hide was intensively scraped for 20 minutes (c. 40 strokes per minute) by 
a right handed person using a unidirectional-transversal scraping action and a working angle of $75-80^{\circ}$. The left edge, in particular the portion closer to the proximal end, was in continuous contact with the hide. Scraping movements started from the ventral face of left lateral edge and continued to the dorsal face of the same edge (negative motion).

In time 2, the same flake was used to scrape the fresh hide of wild boar for 30 minutes (Figure 2). Once again the left lateral side of this piece was used by a right handed person with the same unidirectional-transversal movement.

Thus, the flakes and actions used in these two use wear experiments were the same but with a change in animal and time between the first and second stages - deer in time 1 (20 minutes) and wild boar in time 2 (30 minutes). The change of animal species relates solely to animal available at the time the experiments were conducted. Both animals were similar in size. Time was increased to enhance the surface modifications obtained after the first stage of use.

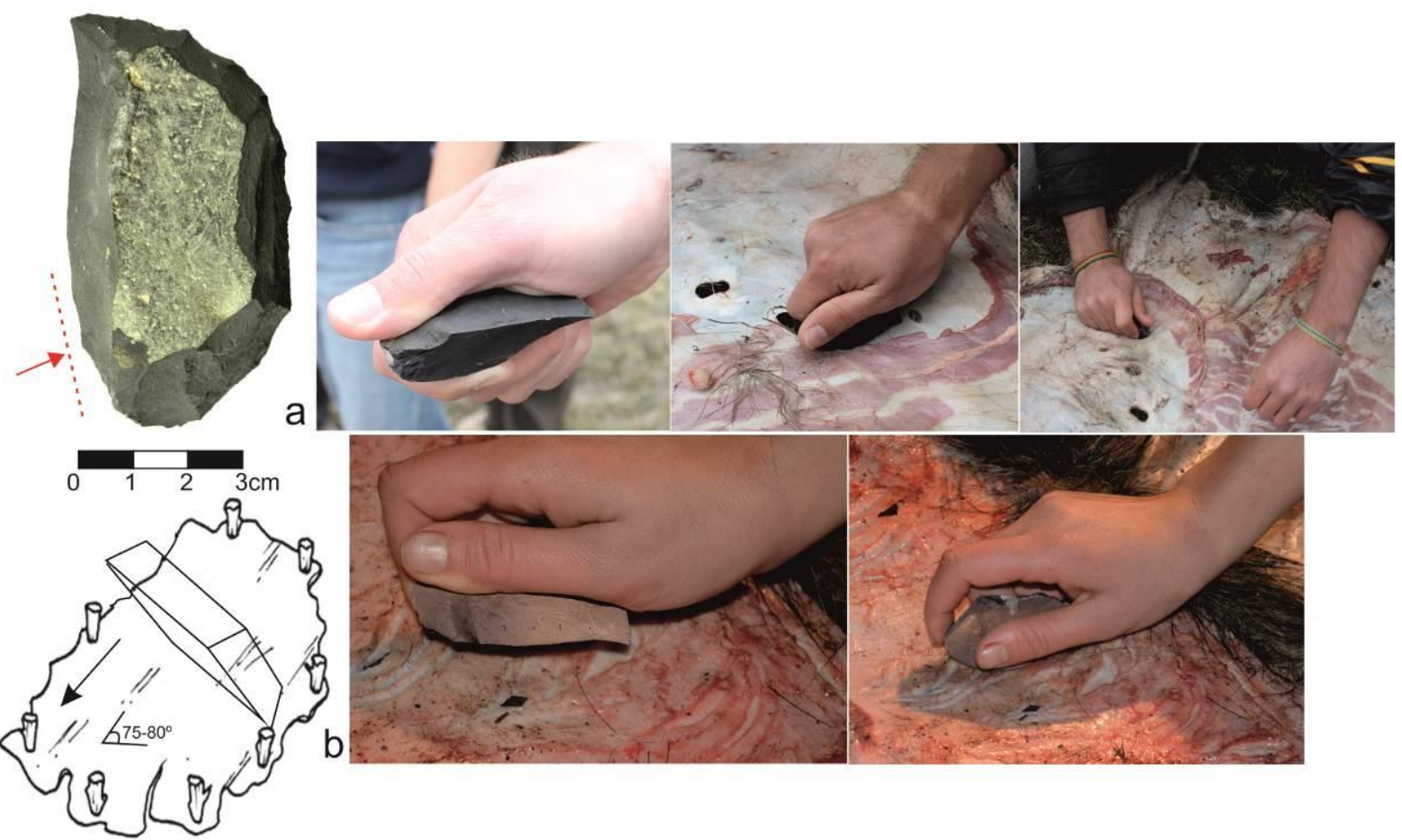

Figure 2. Ishbas 1 - HS1 flake used for scraping fresh hide: a) time 1 - scraping fresh deer hide; b) time 2 scraping fresh wild boar hide. Dashed line on left lateral indicates the most active area of the edge. Arrow indicates direction of tool movement. The illustration below shows direction of movement and the working angle.

\subsubsection{Post depositional surface modification experiments: trampling of basalt flakes}

The first stage of the PDSM experiment was undertaken at Cabárceno Natural Park (Cantabria, Spain) where a population of 70 bears (Ursus arctos - mean weight 250-400 kg) live in semi-wild conditions. Experimental flakes in chert, flint, basalt, obsidian, quartzite and quartz were used. As this experiment is ongoing and the flakes are still being monitored, we present the results of only two basalt flakes (Ishbas1 and Ishbas2). The experimental pieces were placed in contact with the clayey sediment in an area that is continuously and exclusively used by bears (Figure 3). We took coordinates of the experimental area and each piece in it, recorded the orientation of flakes and noted which face (dorsal or ventral) was in contact with the sediment. After 15 minutes, between 15 and 25 bears had passed through the area (Figure 3). 
One piece (Ishbas2) was removed the day after the experiment had begun in order to monitor changes that had occurred after one day. Another basalt flake (Ishbas1) was recovered three months later, and the remaining two basalt pieces are still in the experimental area. It is important to note that all experimental pieces experienced important horizontal and some vertical dispersion (e.g., one was found almost $7 \mathrm{~m}$ from its original position and another at $6.5 \mathrm{~m}$ ) (Figure 4).

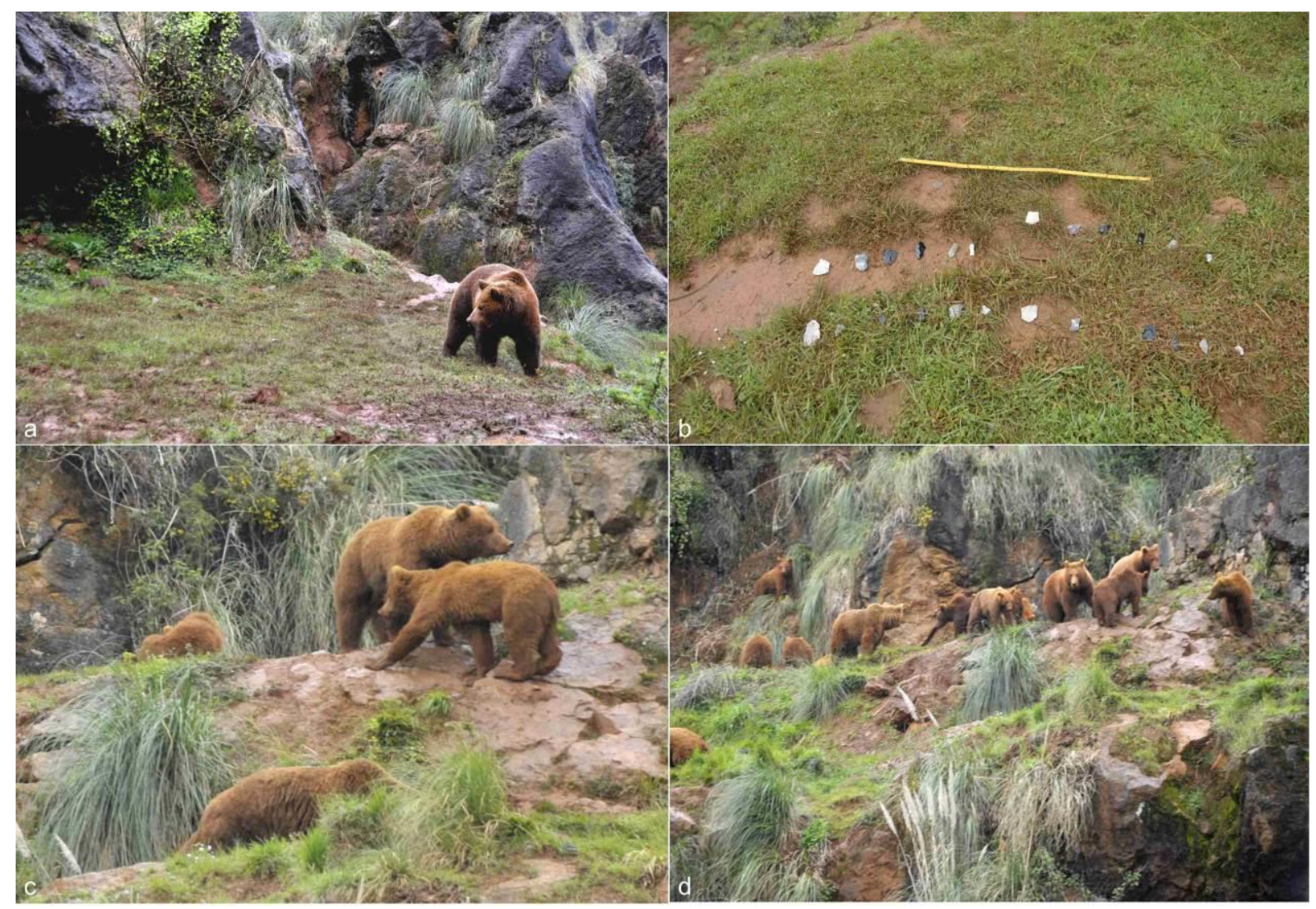

Fig. 3 - Bear trampling experiment: a) area of experiment; b) experimental pieces in experimental area at the start of experiment; $c$ and d) area of experiment 15 to 30 minutes after the experiment had begun.

The second stage of the PDSM experiment included the use of basalt pieces recovered from the bear trampling area and other experimental pieces (e.g., flint, obsidian and quartzite) for a tumbling experiment in a tumbling machine. Instead of using the conventional tumbling machine employed in other taphonomic experiments (Burroni et al. 2002; Fernández-Jalvo \& Andrews 2003; Eren et al. 2011; Vallin et al. 2013), we sought one that would be more adapted to our specific problems, and chose a machine which had been used previously by one of us (Ollé 2003; Vergès 2003). It is a tank made of travertine slabs in which we placed sediment, water and injected pressured air to simulate the type of impacts caused by suspended particles and small gravels during water flow in calcareous environments (Figure $5)$.

The tank is a 60x40x30 cm travertine box with small air-holes in its base and external connections through a hose to a continuous pressured air system. Air flow is controlled by a tap by which pressure can be reduced or increased. When the tap is open the air passes through the hose to enter the tank and comes out through the holes in the base of the tank. When in function the machine produces a generic "boiling water" effect (Figure 5f) which causes movement of fine particles and gravels in the water and impact of gravels against experimental pieces. Flow intensity is not strong enough to cause forceful collisions of 
artefacts, although there is some displacement which can cause slight sliding and dragging of pieces against the travertine floor and walls which may affect their surfaces.

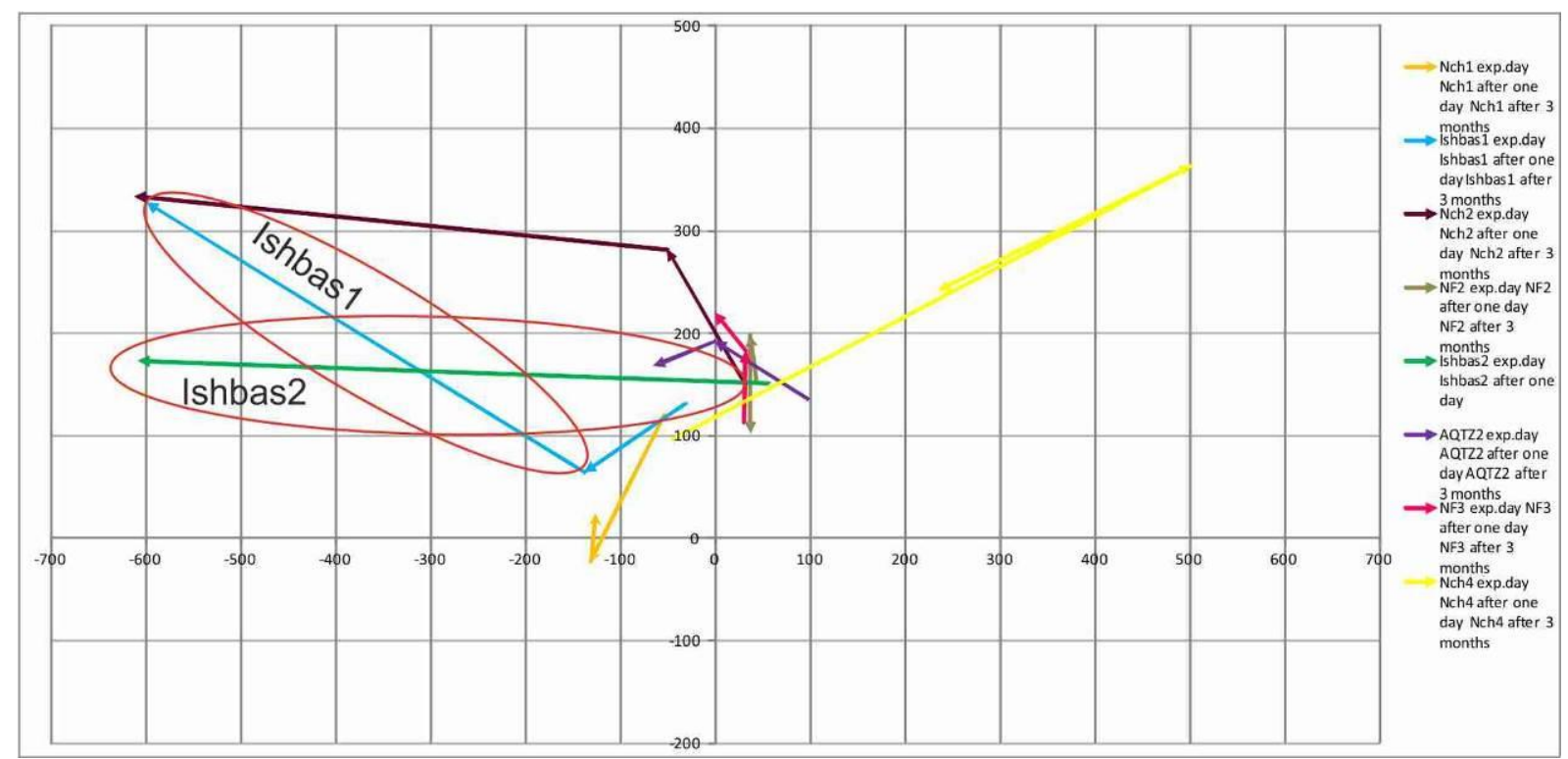

Figure 4. Dispersion of all experimental pieces during the bear trampling experiment in one day and after 3 months. Red ovals indicate Ishbas 1 and Ishbas 2 flakes. Displacement of these flakes from their original place in one day and after 3 months is clearly evident.

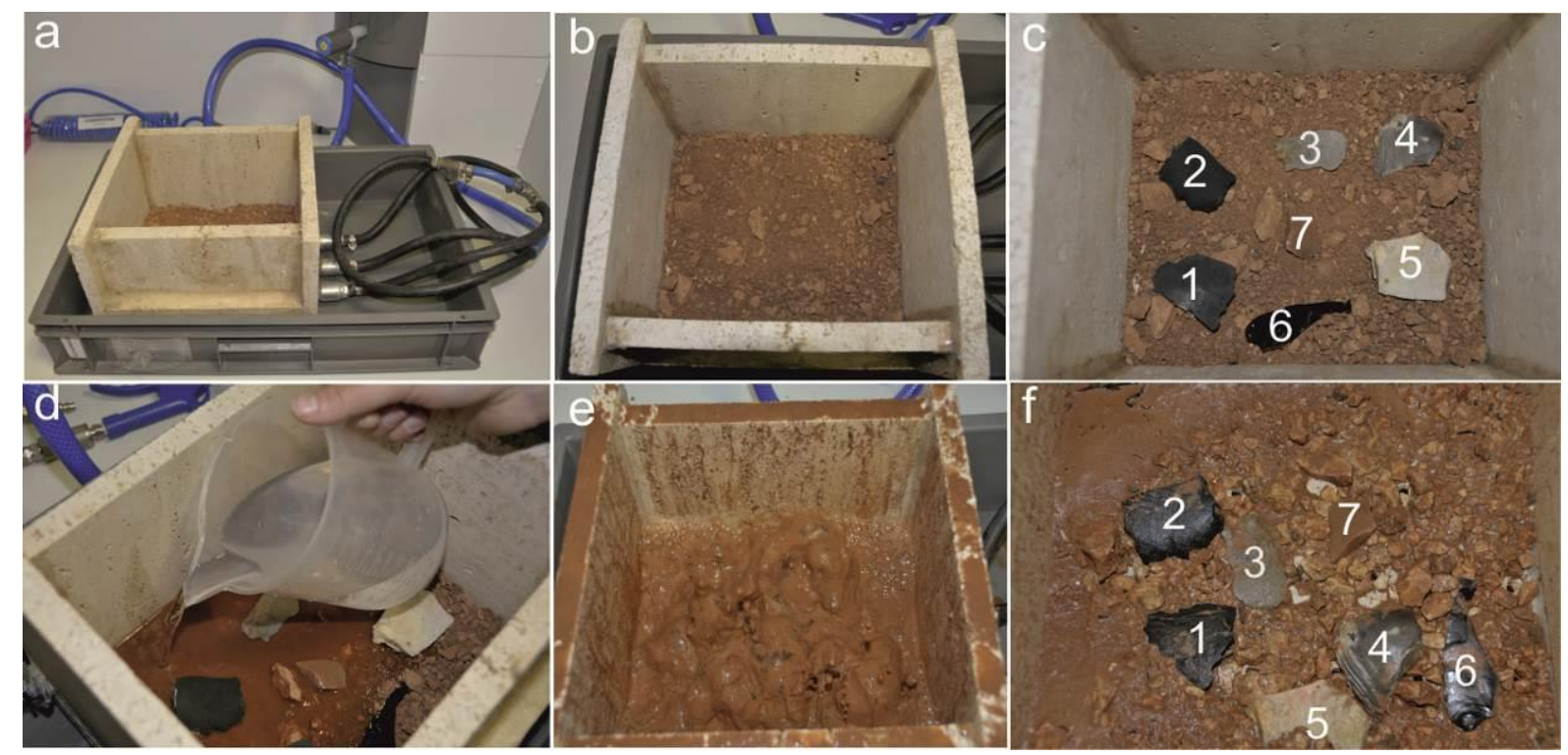

Figure 5. Tumbling experiment: a) travertine tank connected to air source; b) sediment filling; c) experimental pieces on top of sediment layer and their initial distribution; d) covering sediment and flakes with water; e) intensive "boiling" effect; f) distribution of experimental flakes after five hours.

Initially, the floor of the tank was covered with $2 \mathrm{~kg}$ of a gravel-sandy-mud sediment composed of limestone gravels, fine sand, and mud or clay (we tried to avoid quartz-rich sediments as these can provoke aggressive abrasion which does not apply to the experimental or archaeological context). The experimental pieces were placed on top of the sediment layer, each at some distance from the other, and then covered with 2 litres of tap water (Figure 5). The tank was refilled as needed with water and sediment as the intense "boiling" caused these components to overflow through the top of the tank or cracks in the travertine. The first microscopic observation was made after 10 hours using the optical microscope alone to 
monitor any changes to the experimental pieces. Then, they were returned to the tumbling tank and "boiled" for another ten hours (thus 20 hours in total) after which they were taken for detailed macro- and microscopic observation.

\subsection{Post-experimental cleaning of samples and microscopic study}

In the laboratory all experimental pieces were photographed, to record macroscopically visible changes, and individually cleaned in a DERQUIM bath using an ultrasound cleaning machine for 20-25 minutes. After cleaning with soap, the pieces were washed in water under high pressure and then cleaned with oxygenated water for 15 minutes and in an acetone bath for 5 minutes to remove all organic material. Post-experimental microscopic analysis was conducted combining both optical (ZEISS Axioscope A1 - magnification ranging between 50x-500x) and scanning electron (SEM JEOL 6400 - magnification ranging between 25x 2500x) microscopes. To achieve the conductivity required for satisfactory observation when working at high vacuum under the SEM, the samples were coated with a 20 -nm-thick layer of gold. While both microscopes were successful in locating use-wear and post-depositional alterations, the SEM provided a more detailed and better quality (especially when working with high magnifications) view of the irregular textural changes on basalt. As such, the combined use of both microscopes provides results which are highly complementary (Borel et al. (in press)).

Finally, we compared the results of the experimental study with those of the macro- and microscopic study of some archaeological basalt flakes from Azokh Cave (5 pieces were chosen for functional and 2 for PDSM analyses). In this case we used FEI Quanta 600 SEM equipment, at low vacuum mode (which does not require gold coating).

\section{Results}

Macroscopically, after the first stage of experiments, apart from two pieces, none of the experimental pieces showed clear alterations. The exceptions, one used for skinning and one subjected to three months of trampling, showed slight edge damage, moreover, the flake exposed to bear trampling showed slight patina and rounding of dorsal and ventral edges and ridges. After the second stage of experiments, alteration of pieces, when present, was easier to see macroscopically since the gold coating remaining from the first microscopic studies had been partially removed so that any evident change or breakage of the used edge or ridge was visible with the naked eye. Changes or alterations were seen on flakes used for skinning, scraping and exposed to trampling: edge damage and some small fractures on the flake used for skinning, some slight rounding and micro-fractures on the flake used for scraping, and rounding of ridges on the flake exposed to tumbling (Figure 6).

\subsection{Results: Use-wear experiments}

Ishbas1-MC1 (skinning):

After 20 minutes, macroscopic and microscopic edge damage (i.e., micro-flakes, microchips) was visible on the used (distal) edge and especially the most used portion of this edge (Figure 6). Most micro-flakes were small (1-0.02 mm), semi-circular or half-moon in shape, with reflected terminations, and mainly located on the ventral face. Edge rounding and edge smoothing were also observed (mostly on the highest point of the flake surface) but were neither intensive nor continuous. Polish with a dull and grainy texture was not well developed. Under the SEM, the slightly polished areas have a few striations parallel to the edge. Obviously, use-wear modifications were more developed after the second stage (50 
minutes of use in total) of the experiment. Apart from edge damage, clearly developed, continuous step fractures appeared along the edge, mainly trapezoidal and irregular in morphology and with reflected terminations. At times, fractures were also linear (Figure 7 $a_{3} \& b_{3}$ ). The edge showed widespread rounding, abrasion and some plastic deformation with soft, parallel-to-the-edge linear features (including bands of polish and striations; Figure 7c \& d) that are clearly evident and accentuated in the area of the edge where step fractures finish. This is reasonable as this was the first area to make contact with the animal skin. The subsequent, unidirectional longitudinal movements of the piece helped concentrate and accentuate development of rounding, polish and abrasion, especially on the areas below the step fractures.

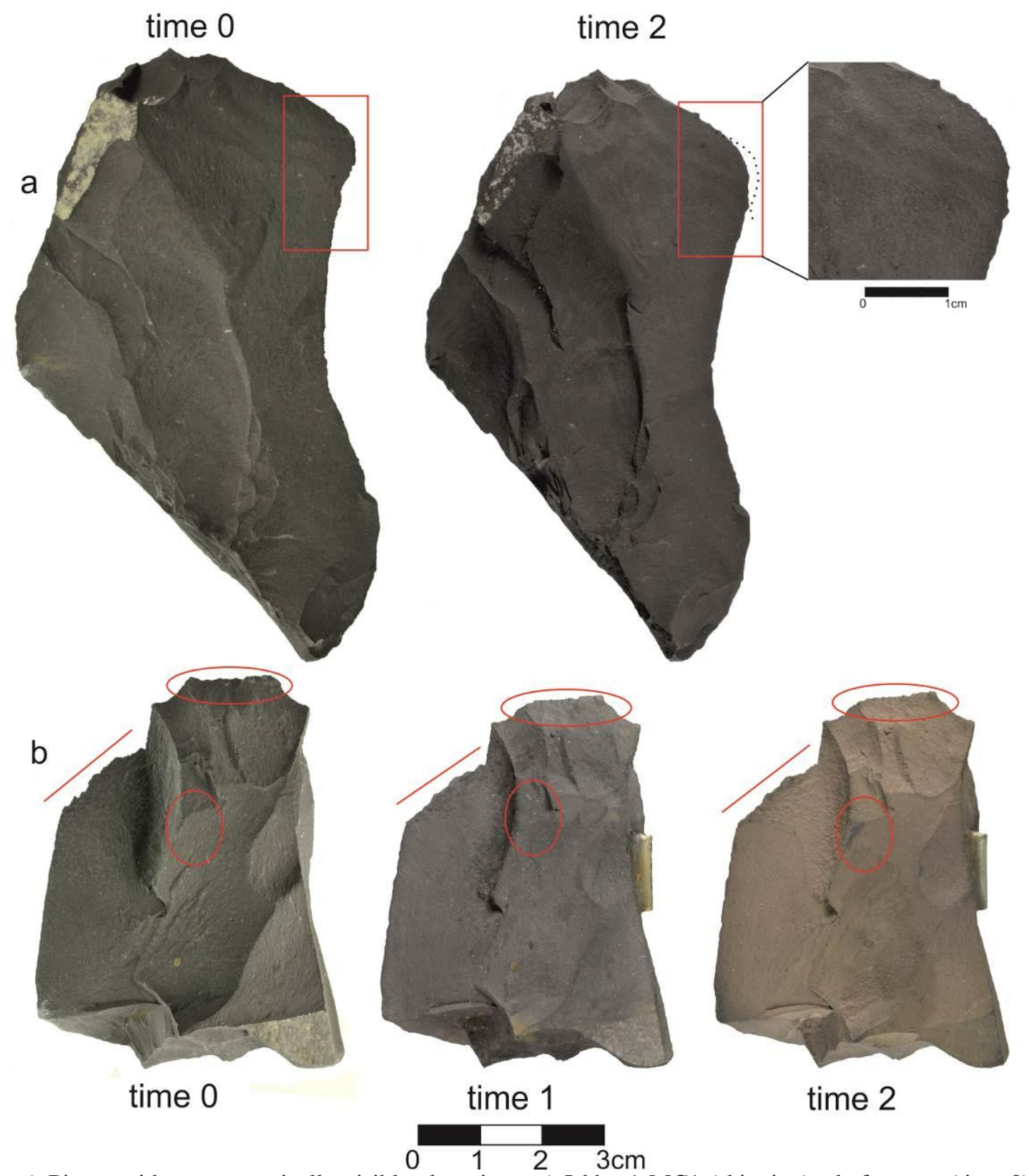

Figure 6. Pieces with macroscopically visible alterations: a) Ishbas1-MC1 (skinning) - before use (time 0) and after total of 50 minutes of use (time 2). The rectangle shows the most used and most altered portion of the edge, and the dashed line above the edge after time 2 indicates changes in the edge in comparison with time $0 ; b$ ) Ishbas1(trampling and tumbling) - before PDSM experiments (time 0), after bear trampling experiment (time 1) and after tumbling experiment (time 2). The ovals and lines indicate alterations visible macroscopically. 


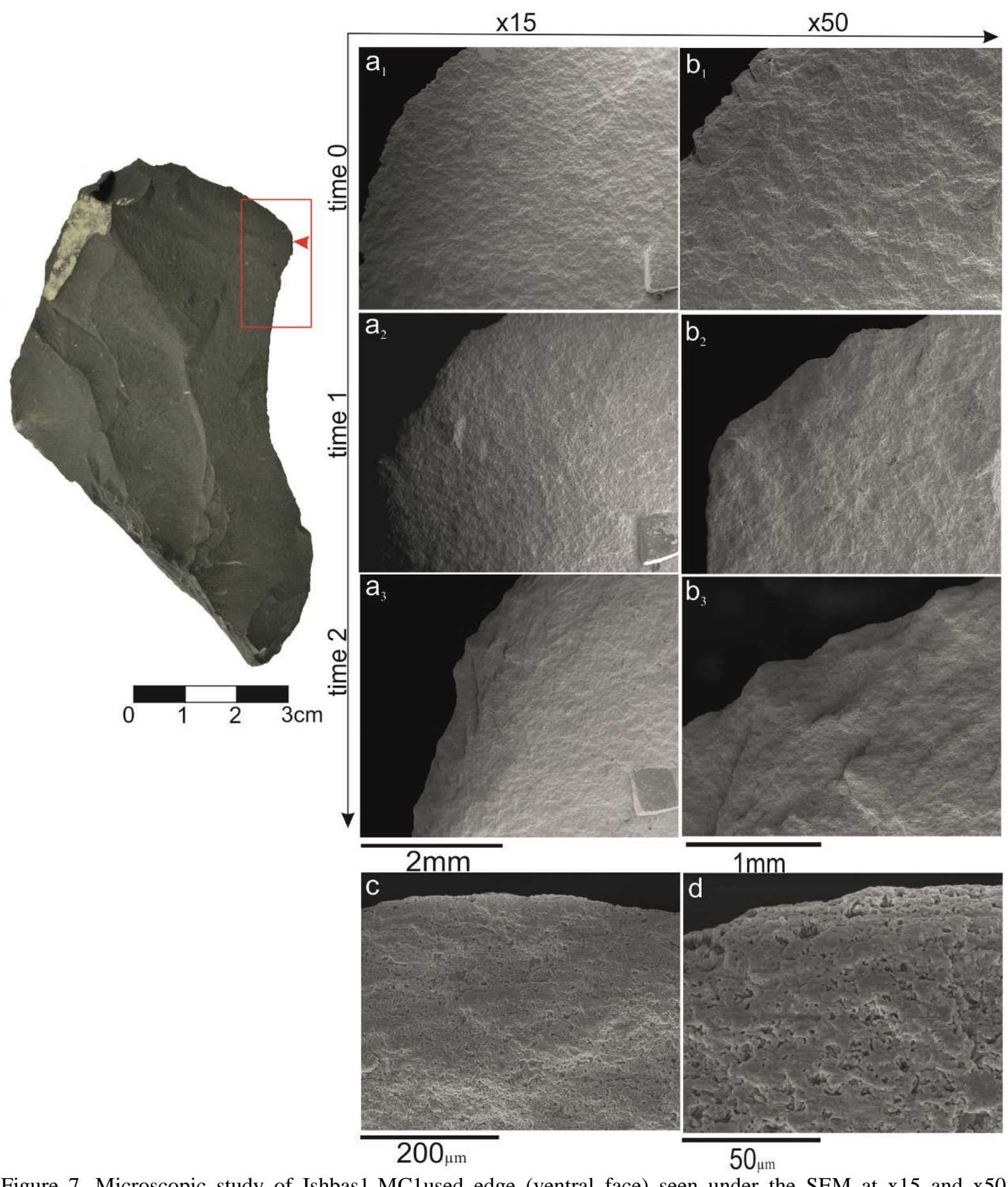

Figure 7. Microscopic study of Ishbas1-MC1used edge (ventral face) seen under the SEM at x15 and x50 magnifications. The rectangle on the edge indicates the portion of the edge used most often and the arrow indicates the exact point shown in this image: $\left(a_{1}-a_{3}\right)$ the same portion of the edge unused $\left(a_{1}\right)$, after 20 minutes $\left(a_{2}\right)$ and after 50 minutes $\left(a_{3}\right)$ of use and at x15 magnification; $b_{1}-b_{3}$ show the same portion of the edge under higher (x50) magnification at time $0\left(b_{1}-\right.$ unused), after time $1\left(b_{2} 20\right.$ minutes of use) and time $2\left(b_{3}\right.$ total of 50 minutes of use); c \& d are examples of widespread use-wear traces on the edge after 50 minutes of use with evidence of abrasion and oriented striations seen under the SEM at x250 and x1000 magnifications respectively.

\section{Ishbas1-HS1 (scraping):}

Macroscopically, except for a few micro-flakes, almost no changes were present after 20 minutes (time 1). Microscopically, edge damage was observed on the lower left side (used edge); micro-flakes and micro-chips over the used edge were predominantly semi-circular and 
triangular in shape with reflected terminations, and 1.5-0.7 $\mathrm{mm}$ in length. Most edge damage was on the ventral face. Slight-to medium-rounding was evident over the used area starting from the ventral face and extending transversally to the dorsal face. Some polish, with a dull, grainy and, at times, smooth texture, extended from the ventral to dorsal face (Figure 8). No heavy rounding, polish or pitting was observed at this stage. Striations were more commonly observed on this piece than that used for skinning, but in this case they were perpendicular to the edge (Figure $8 \mathrm{a}_{2}-\mathrm{c}_{2} \& \mathrm{~d}_{1}$ ). After 50 minutes (time 2), the used edge showed generalised abrasion, rounding and clear polish (Figure $8 a_{3}, b_{3} \& c_{3}$ ). Transversally developed rounding started from the ventral face (i.e., area of impact) and moved to the dorsal face. The surface underwent strong plastic deformation leading to a closed pattern of polish (Figure $8 \mathrm{~d}_{2}$ ). Perpendicular striations, seen clearly after 20 minutes, now appeared practically obliterated by the polished areas. Polish was very well developed and very smooth at the maximum contact areas (Figure $8 \mathrm{~d}_{2}$ ). Edge damage was limited to a few micro-flakes and microchips which were mainly semi-circular or half-moon in shape, and $1.7-0.8 \mathrm{~mm}$ in length.

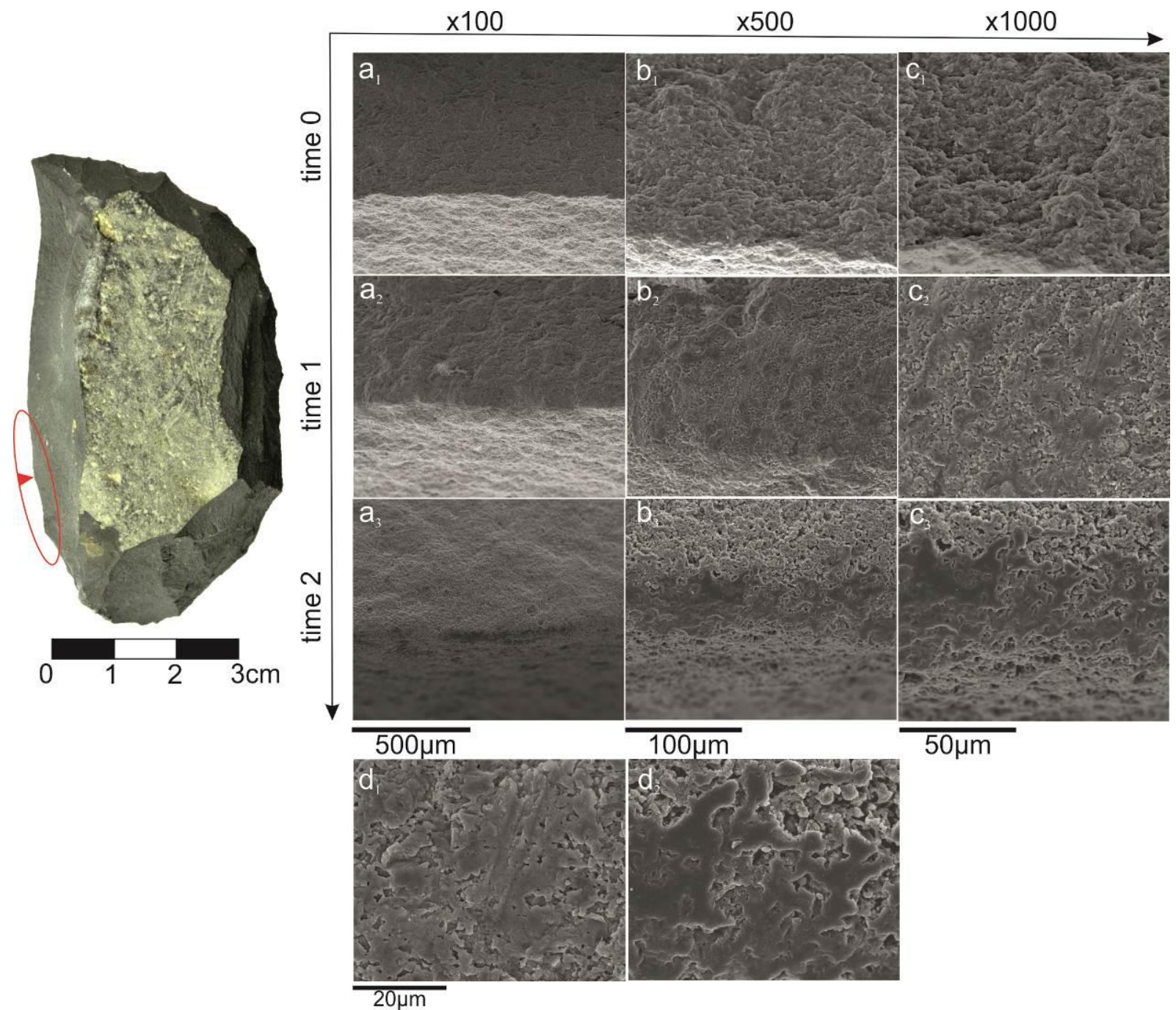

Figure 8. Microscopic study of Ishbas1-HS1 used edge (ventral face) seen under the SEM; circle indicates the most used portion of the edge and the arrow shows the exact point at which these images were taken: $\left(a_{1}-a_{3}\right)$ the same portion of the unused edge $\left(a_{1}\right)$, after 20 minutes $\left(a_{2}\right)$ and after 50 minutes $\left(a_{3}\right)$ of use at x100 magnification; $\left(b_{1}-b_{3}\right)$ the same portion of the unused edge $\left(b_{1}\right)$, after 20 minutes $\left(b_{2}\right)$ and after 50 minutes $\left(b_{3}\right)$ of use at $\times 500$ magnification; $\left(c_{1}-c_{3}\right)$ the same portion of the unused edge $\left(c_{1}\right)$, after 20 minutes $\left(c_{2}\right)$ and after 50 minutes $\left(c_{3}\right)$ of use at x1000 magnification; $\left(d_{1}-d_{2}\right)$ a detail of use-wear traces after 20 minutes $\left(d_{1}\right)$ and after 50 minutes $\left(d_{2}\right)$ of use at $x 2000$ magnification. 


\subsection{Results of Post-Depositional Surface Modification experiments}

Ishbas1 and Ishbas2 (bear trampling and tumbling experiments):

One piece was displaced by almost $6.50 \mathrm{~m}$ in one day, and the other displaced by almost $1 \mathrm{~m}$ in one day and $7 \mathrm{~m}$ in two months. The face of each piece originally in contact with the sediment had flipped over. Macroscopically, one flake (Ishbas1) showed clear edge damage or breakage, rounding of edges and ridges, and had developed a slight whitish patina. No macroscopic post-depositional signs were visible on Ishbas2. Microscopically, edges and ridges of both pieces had damage and small breaks, but more so on the Ishbas 1 piece. These were mainly half-moon, triangular and trapezoidal fractures varying in size from 3 to $0,5 \mathrm{~mm}$, distributed irregularly over dorsal and ventral faces. Rounding of the most elevated parts of the edge and general surface, and slight granular polish were observed on both pieces (Figure 9). Under the SEM, small linear features $(1-0.2 \mathrm{~mm})$, distributed perpendicular to some ridges, were evident on both pieces. No further changes were observed on these pieces.

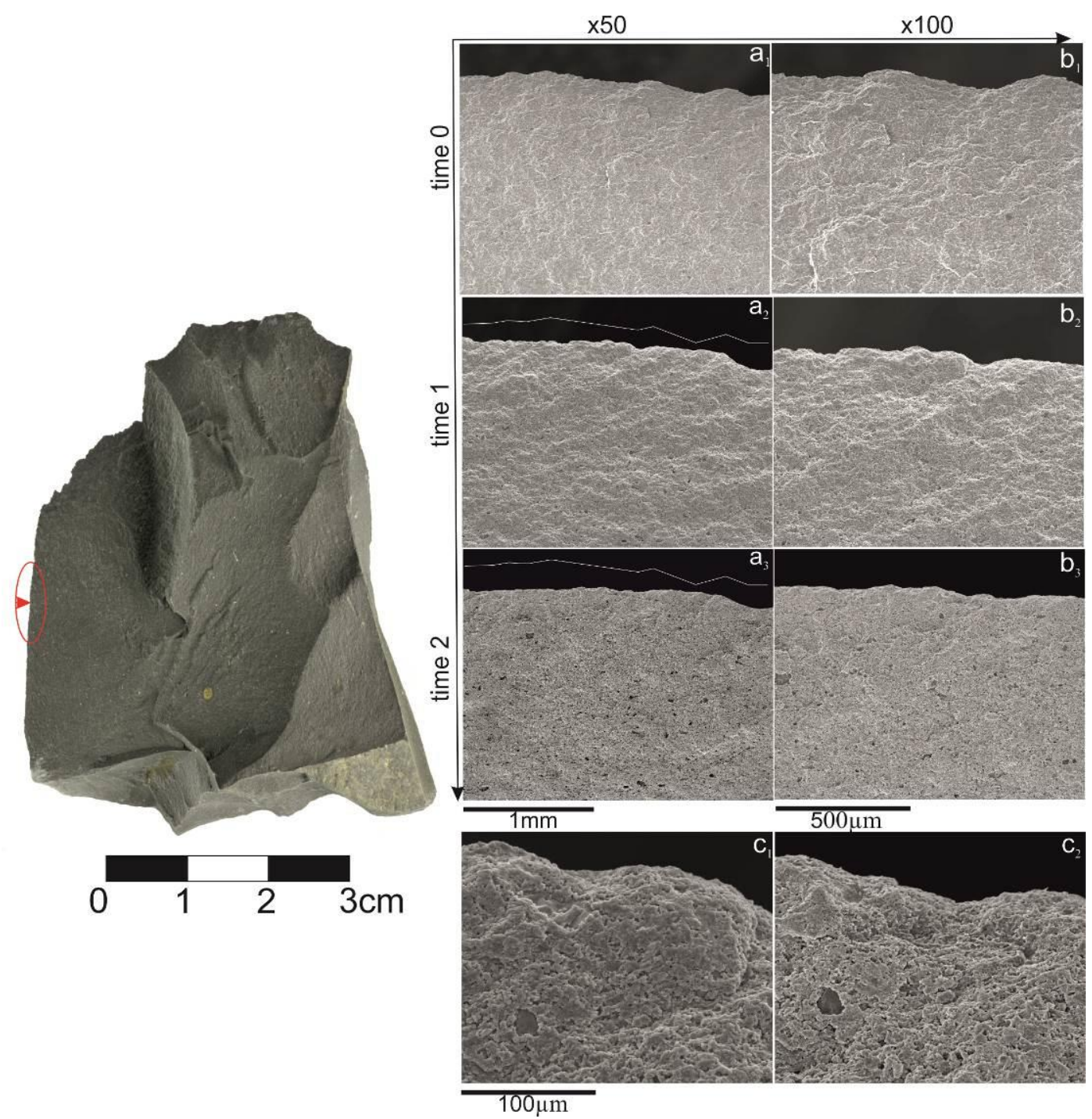

Figure 9. Example of edge damage seen on Ishbas1 used for the PDSM experiments. The control point is taken on the dorsal left lateral in the area indicated by circle and arrow, using the SEM at x50 - x100 magnifications; $a_{1}-a_{3}$ show the same portion of the edge at its original stage $\left(a_{1}\right)$, after 3 months of bear trampling $\left({ }_{2}\right)$ and 20 hours of tumbling (a3) experiments seen at x50 magnification. The lines along the edge in $\mathrm{a}_{2}$ and $\mathrm{a}_{3}$ show changes of the edge in comparison with original stage of the edge $\left(a_{1}\right) ; b_{1}-b_{3}$ show the same portion of the edge at x100 magnification; $c_{1} \& c_{2}$ show a detail of edge damage and some rounding and abrasion after trampling $\left(c_{1}\right)$ and tumbling $\left(c_{2}\right)$ at $\times 500$ magnification. 
After subjected to tumbling for 20 hours, all experimental pieces had shifted from their initial location (Figure 5) indicating that the intensive "boiling" process of the water and sediment mixture had caused continuous movement of, and contact between pieces and with the tank's travertine floor and walls. After this second stage, except for the obsidian flake which showed striations on its surface, it was difficult to see macroscopically many visible changes on the flakes, in particular on basalt flakes, although these latter pieces showed development of a whitish (N9 white and N8 very light grey) patina and some rounding of ridges. The first microscopic observation, using an optical microscope, was carried out after 10 hours to record any changes on flake surfaces. At this time there was evidence of mechanical alteration such as rounding and abrasion of edges and ridges in places, and presence of some striations and edge damage (Figure 10). The pieces were then returned to the tumbling machine for another 10 hours. After a total of 20 hours of "boiling", the pieces underwent detailed microscopic analysis, this time using both optical and SEM microscopes (Figure 9).

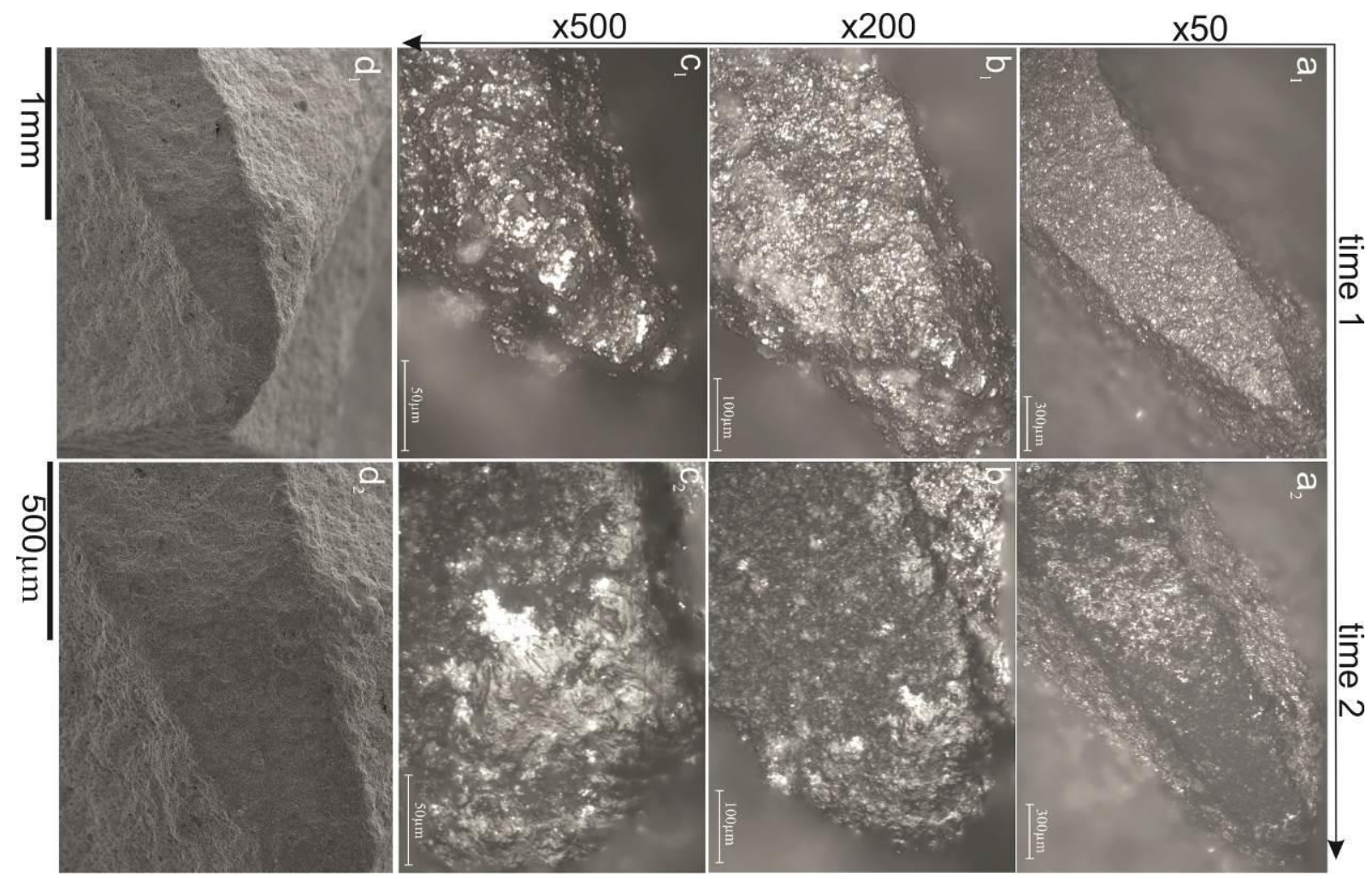

Figure 10. An example of important mechanical alteration of the ridges on the PDSM experimental pieces seen under the optical microscope at x50 $\left(\mathrm{a}_{1} \& \mathrm{a}_{2}\right)$, x200 ( $\left.\mathrm{b}_{1} \& \mathrm{~b}_{2}\right)$ and x500 $\left(\mathrm{c}_{1} \& \mathrm{c}_{2}\right)$ respectively after 10 and 20 hours of tumbling; $d_{1}$ and $d_{2}$ images are the same area after 20 hour of tumbling under the SEM at x50 \& x100 magnifications.

Microscopic study clearly showed the presence of an important degree of mechanical alteration. In particular, the most elevated parts of ridges and edges displayed a substantial, but not very heavy, degree of rounding and polish at times with randomly distributed striations from 1.2-0.4 mm in length. Some features, in particular edge rounding, polish and abrasion, were similar to those seen on flakes used in the functional experiments (Figure 11), although along the edge, usually on its more elevated areas. Furthermore, as with flakes used in the functional experiments, rounding and polish of PDSM pieces did not develop until plastic deformation of the flake surface had occurred. These features were lighter and irregularly developed over the edge and 3-5 mm from it. Polish was generally granular with 
no pitting and no bright spots. The edge damage observed on these pieces was irregular, discontinuous, and in the form of trapezoidal and half-moon-shaped micro-flakes that ranged between 1.5-0.6 mm.

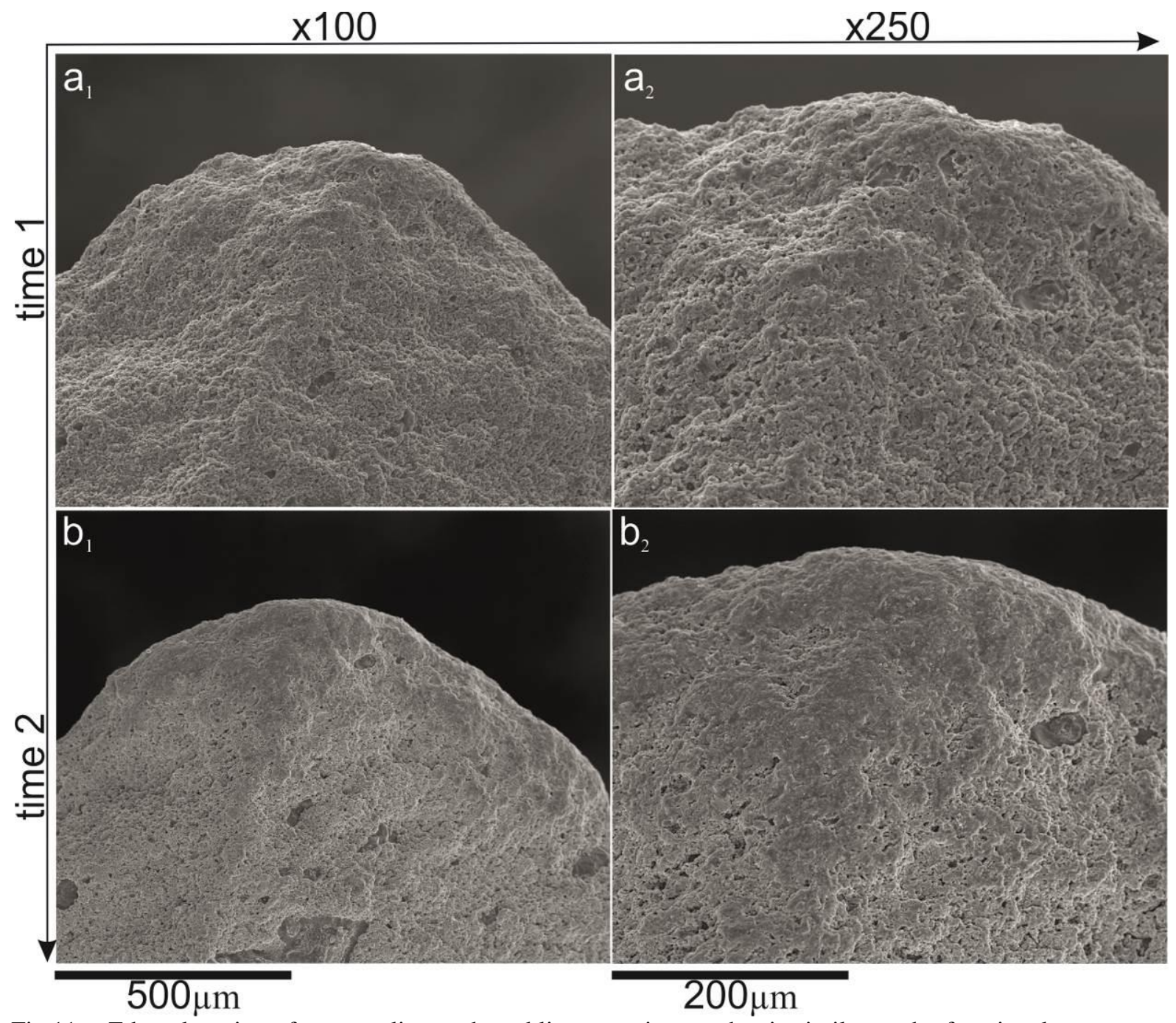

Fig.11 - Edge alteration after trampling and tumbling experiments that is similar to the functional traces seen under the SEM at x100 \& x 250 magnifications: $a_{1} \& b_{1}$ are the same portion of the edge after 3 months of bear trampling showing some slight rounding and abrasion; $b_{1} \& b_{2}$ are the same portion after 20 hours of tumbling with more developed alteration.

Micro-flaking of the edge generates fresh surfaces with almost no further alterations. In places, the highest part of ridges showed irregular damage which developed until the occurrence of plastic deformation.

After twenty hours in a tumbling machine, the effects of PDSM on flakes can be characterized as being partially and lightly developed in places.

\section{Discussion}

As well as use, several processes can cause alterations to lithic artefacts. Some processes are related to artefact production and transport, some can be related to animal and human trampling or other natural agents that transform the archaeological sediment after the artefact has been abandoned. Whatever the process is, it may pose difficulties in the interpretation of use-wear features as all processes may produce alterations that can be confused with those associated with function, or they may overlap with each other. Basalt artefacts are no 
exception to this general concept, although the olivine basalt used in this study was quite tough and resistant to alterations caused by function and trampling or tumbling.

The preliminary results of these experiments demonstrate a set of use-wear and PDSM features which, although they need to be developed and synthesised, should be taken into account in future studies. In particular, our results showed the following:

1) Edge damage or micro-flaking was produced on edges during both functional and PDSM experiments, although micro-flaking (i.e., step fractures) was characteristic only for pieces used in functional experiments, in particular the flake used for skinning during 50 minutes (Table 2). None of the PDSM flakes showed step fractures. Many authors (e.g., Tringham et al. 1974; Odell 1981; Richards 1988) have discussed difficulties in distinguishing micro-flake characteristics and their distribution in order to determine material used (e.g., hide, bone, meat, etc.) or actions applied (e.g., cutting, scraping, skinning, etc.). The same problems apply to the basalt flakes used in our use-wear experiments. Edge damage was evident on pieces used for skinning and scraping fresh hide. Although there is a little variation in micro-flake or edge damage size, all other characteristics (e.g., location, shape, distribution) are similar. However step fractures were characteristic only of the flakes used for skinning. Flakes from the trampling and tumbling experiment also showed edge damage, but it differed slightly (e.g., larger in size, irregular distribution, shape) from flakes used for skinning and scraping (Table 2). Edge damage affecting these pieces created fresh surfaces that later did not become altered or were only partially and slightly altered. Edge damage created fresh surfaces during the functional experiments also, but with further use these fresh areas displayed widespread alteration. We think that these differences may help to distinguish between edge damage resulting from of use with that from PDSM.

2) Rounding of edges and, at times, ridges resulted from both use and PDSM in the first stages of experiments. Although more pronounced in use experiments (hide scraping in particular) after 20 minutes (Table 2), it was quite difficult to mark clear differences between rounding caused by use or by PDSM as no pieces showed heavy rounding or polish. This could be related to: a) the need for a longer period of use, although some authors (Richards 1988; Rodríguez Rodríguez 1998) indicate an important presence of rounding of experimental basalt pieces after 5 minutes of use; b) the type of basalt (fine grained and homogenous) is more resistant to rounding or polish formation. However, after 50 minutes of use and of combined PDSM experiments all pieces showed clear evidence of rounding and abrasion, although not as well defined nor well developed as would occur with other rocks after such a long period of use. While rounding and abrasion affected all the used edge of skinning and hide-working flakes, on the PDSM pieces such features were sporadic but clear on the most elevated parts of edges and ridges (Table 2). There were some differences regarding the distribution and development of rounding and abrasion among flakes used for functional experiments. On the flake used for skinning, edge rounding and abrasion were lighter and distributed parallel to the used edge, particularly in the area that did not make first contact with the experimenting material. The flake used for fresh hide scraping was slightly different in that edge rounding and abrasion were more developed and distributed along the whole edge. In addition, rounding extended transversally from the used ventral edge onto the dorsal edge. Richards (1988) also noticed differences in rounding or abrasion distribution and development between basalt pieces used for different actions. He suggests that longitudinal actions rarely produce significant edge rounding, but rounding is much greater and more extensive on tools used for scraping. The results of our PDSM experiments show occasional rounding and polish quite similar to use-wear features (e.g., slight rounding and polish with some micro fractures), in particular on the flake edge used for skinning. Microscopic observation of the whole piece (i.e., not only the edges but other parts of the flake) can be helpful, as alterations caused by use are normally distributed over flake edges, but alteration 
that is distributed irregularly over the edges and the other parts (e.g., ridges, surface) of the flake, may be an important basis on which to consider PDSM (Levi-Sala 1986; Burroni et al. 2002). However, such a concept may be difficult to apply when working with archaeological material since there can be an overlapping of both use-wear and post-depositional alterations, or other features may develop which are similar to some use-wear traces on an edge that can lead to faulty analysis and misinterpretation.

3) After 20 minutes of use or 3 months of bear trampling polish was not well developed on any experimental tool (Table 2). There was slightly more evidence of polish on flakes used for skinning and particularly for fresh hide scraping than on flakes used for trampling and tumbling, but this polish was visible only under the SEM using high magnification. All flakes showed very similar polish characteristics (a dull and mainly granular texture). No pitting or bright spots were recorded on polish as other authors have indicated (Richards 1988). Therefore, in the initial stages, we do not believe that rounding and polish can be considered as a feature that differentiates between use and post-depositional alteration. After 50 minutes of use or 20 hours of tumbling, although development of polish and rounding was not excessive, some noticeable differences were present. On areas of the flake edge used for scraping, well developed, smooth and pitted polish transversally oriented from ventral to the dorsal edge was evident. Polish on the flake used for skinning was lighter and parallel to the used edge. While polish on the flake used for fresh hide scraping could be identified under the optical microscope (x100 - x200), polish on the flake used for skinning could be seen only under the SEM (from 250x). In contrast to flakes used in functional experiments, after 20 hours of tumbling, although flakes used in the tumbling experiment developed polish on the elevated areas of their edges and ridges, it was neither widespread nor oriented in any particular way.

4) Linear features or striations were present on all pieces but were especially well developed on the hide-scraping and bear-trampling flakes after 20 minutes of use and 3 months of bear trampling respectively (Table 2). Linear features were better oriented on flakes used in the functional experiments (e.g., parallel to the flake edge used for skinning and transversal to the direction of movement or perpendicular to the flake edge used for fresh hide scraping, smaller in size, in groups). They appear as bands of compressed material and as true striations (or narrow grooves). Linear features varied in size, organisation and location on PDSM flakes. After 50 minutes of use, these linear features or striations seen after time 1 (20 minutes of use), were practically invisible, or at times slightly visible under the plastic deformation of edges of the flakes used for skinning and fresh hide scraping. We believe that this "disappearance" of striations may be related to extensive compacting or plastic deformation of grains (caused by longer use) that are finally ejected from the stone. After tumbling, the two basalt flakes developed some short, dispersed and unevenly distributed striations evident on areas with most polish. This was particularly noticeable on one flake. Therefore, we believe that more rigorous recording and control of linear features or striations may be an important factor in distinguishing use-wear from post-depositional alteration on basalt pieces.

5) Wear on basalt was more attritional than on other rocks. Plastic deformation, as occurs with siliceous materials (Ollé \& Vergès 2008), is less evident here. Nevertheless, it was documented on flakes used for functional experiments, especially after 50 minutes (time 2). The development of wear on basalt flakes responds primarily to regularisation of the relief by removal of asperities, and only on the areas of maximum contact with the worked material, the surface shows clear signs of plastic deformation (which leads to the smooth polished areas mentioned above).

Although there was no plastic deformation evident on the edges of PDSM flakes, occasionally it occurred on some of the highest ridge areas. This may be related to greater 
trampling or tumbling pressure on the ridges which are more elevated than other parts of the flake. The extent to which plastic deformation resulting from use differs from that from PDSM requires further study; at this stage it can be considered as a factor to distinguish use from PDSM on basalt pieces by its location and orientation.

6) When comparing the experimental results with those seen in the archaeological materials of Azokh Cave, we realised that difficulties related to the recognition of alteration (functional alteration in particular) on basalt were greater on archaeological pieces. We selected five well-preserved basalt pieces for functional and two others for PDSM studies. The main characteristics evident on flakes in the functional study were some edge damage (e.g., micro-flaking) (Figure $12 \mathrm{a}_{1}$ ) and some light and isolated rounding of edges that may be related to tool use (Figure $12 \mathrm{a}_{2} \& \mathrm{a}_{3}$ ). The general techno-typological character of flakes (e.g., suitable size, morphology, working edge, continuous retouch, etc.) supports our hypothesis for tool use. We suggest that the limited wear features may relate to a short period of use during which flakes developed quite light use-wear features, as confirmed by our functional experiments (the skinning experiment in particular). In some cases these features can be identified only under high magnification in the SEM. We faced an additional problem with the archaeological basalt flakes; it was impossible to observe them under the SEM at high vacuum mode as basalt is composed of percentages of $\mathrm{Ca}$ that could easily be destroyed by the nitro-hydrochloric acid solution required for removing gold coating. Consequently, we had to use the SEM low vacuum mode of observation, which does not require gold coating, but makes it more difficult to see possible use-wear traces, especially when these are light or poorly developed.

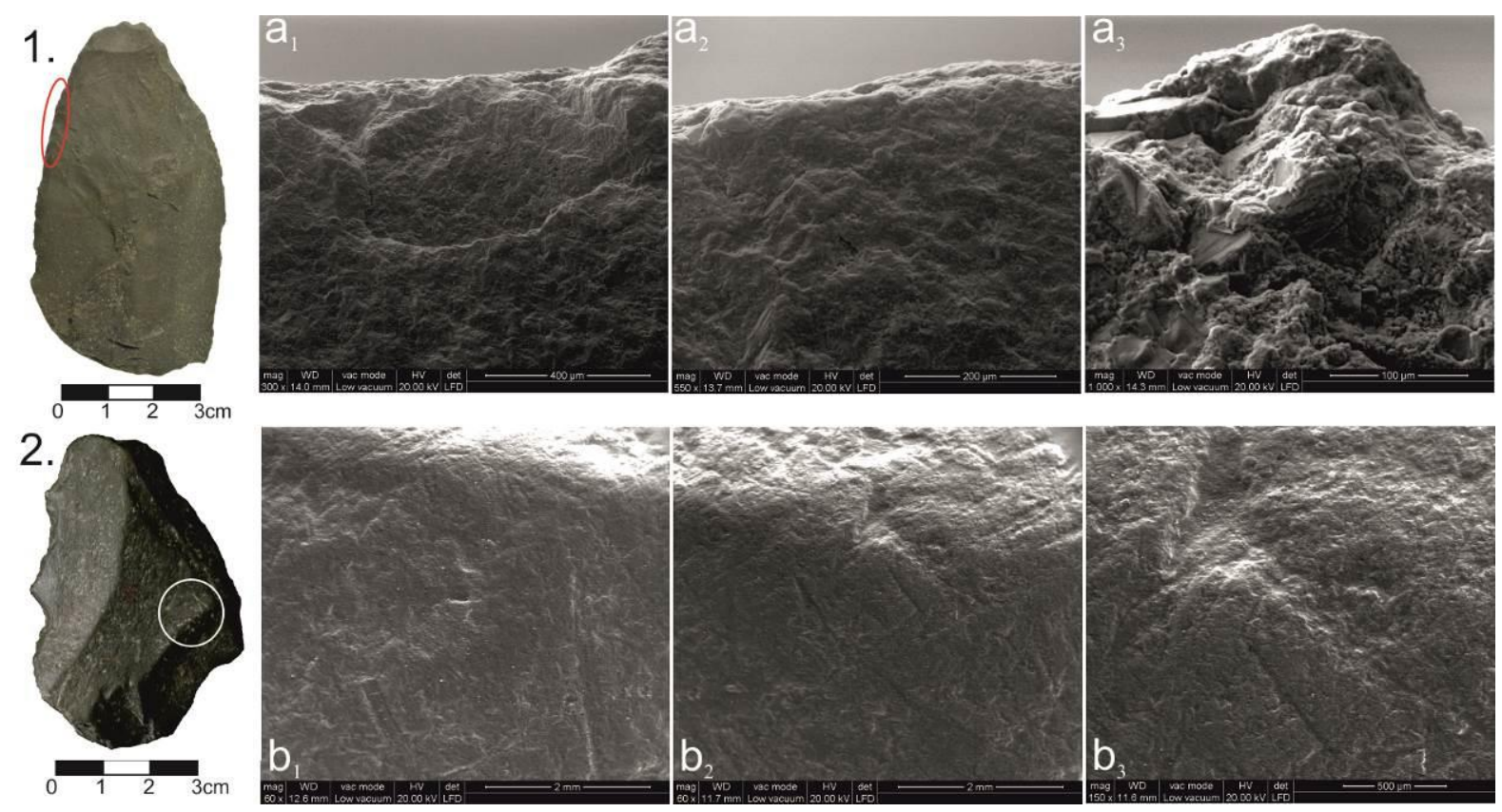

Fig. 12 - Examples of wear and PDSM features on some of the basalt archaeological flakes observed under the SEM (low vacuum mode): top line, artefact I49-unII-32-2010 - left lateral edge (area studied is circled) with evidence of micro-flaking $\left(a_{1}\right)$, edge damage with some light rounding $\left(a_{2}\right.$ and $\left.a_{3}\right)$ seen at x300, x500 and x1000 respectively; Lower line - dorsal surfaces of archaeological basalt flakes (area studied is circled) with generalised heavy rounding, abrasion and randomly distributed striations $\left(b_{1}-b_{3}\right)$ seen at x60 and x150 magnifications.

In contrast to the functional pieces, the PDSM flakes showed clear evidence of rounding, abrasion and polishing with widespread, randomly distributed, short and long striations over the entire flake surface. Many of these alterations can be seen macroscopically (Figure $12 b_{1}-$ 
$b_{3}$ ). Similar alterations were present on the experimental pieces. The only difference we noted was that while alterations of experimental flakes were occasionally developed, especially on the most elevated areas of the flake surface, on archaeological pieces these alterations were widespread and expanded over the whole surface. Apart from this, the degree of alteration was more pronounced on the archaeological than the experimental flakes.

Our experimental results are at a preliminary stage. It is evident that the experimental and archaeological sample needs to be expanded to ensure valid quantitative and statistical studies and reinforce our hypotheses. Nevertheless, based on our results we believe that at Azokh Cave, bears (Ursus spelaeus) affected the PDSM of lithic and faunal assemblages (Asryan et al. in press and Marin-Monfort et al. in press) as is indicated at many other bear den sites (Baryshnikov \& Hoffecker 1994; Kuhn et al. 1996; Stiner et al. 1996; Golovanova et al. 1999; Stiner 1999; Quiles et al. 2004; Moncel \& Rivals 2011). The results of our bear trampling experiment clearly demonstrate that in a short period of time, bears can cause horizontal and some vertical dispersion of artefacts as well as some macro- and microscopic alterations on them. We believe that once the bear-trampling experiment has run for a longer period, it will provide new and much clearer data. At Azokh Cave, some stone tools of different raw materials, including the basalt discussed in this paper, show heavy post-depositional alteration which suggests that bears may not have been the only agents of post-depositional alterations. Two potential interpretations can be considered here: 1) the archaeological material has been affected by post-depositional processes (other than trampling) such as transport caused by energetic water flow in the site. Such an interpretation is virtually impossible as recent sedimentological, stratigraphic and site formation studies (Fernández-Jalvo et al. 2010; Murray et al. 2010; Murray et al. (in press)) indicate no presence of strong, water-induced movements in the current excavation area in which the studied assemblages were found. 2) Some heavily altered artefacts may have been transported from elsewhere (e.g., a nearby river valley) for re-use or recycling purposes, abandoned in this area of the cave and subsequently exposed to further alteration. Although possible (Vaquero 2011), this is still a weak hypothesis as there is no evidence (e.g., later retouch, re-shaping, patina and different lustre, etc.) for the re-use and recycling of the altered archaeological basalt pieces (although there is some evidence for recycling of other pieces on the site). We must conduct further in-depth studies related to the possible transportation of some of these lithic artefacts from riverside locations which may explain the heavy rounded and polished character of these pieces.

Table 2. Summary of relative presence of the main wear features taken into account for skinning, fresh hide scraping, trampling and tumbling experiments at time 1(20 minutes of use and 3 month of bear trampling) and time 2 (total of 50 minutes of use and 20 hours of tumbling). *By 'macro modifications' we refer to macroscopically visible edge damage or fractures and patina formation.

\section{Experiments}

Time 1

Time 2

\begin{tabular}{lcccccc}
\hline $\begin{array}{l}\text { Surface } \\
\text { modifications }\end{array}$ & Skinning & $\begin{array}{c}\text { Fresh hide } \\
\text { scraping }\end{array}$ & $\begin{array}{c}\text { Bear } \\
\text { trampling }\end{array}$ & Skinning & $\begin{array}{c}\text { Fresh hide } \\
\text { scraping }\end{array}$ & Tumbling \\
\hline Macro-modifications* & scarce & scarce & common & common & scarce & scarce \\
Micro-flaking & common & scarce & common & very common & scarce & common \\
Rounding of edges \& ridges & scarce & common & scarce & common & very common & common \\
Polish development & scarce & common & scarce & common & very common & common \\
Linear features & scarce & common & scarce & scarce & scarce & common \\
\hline
\end{tabular}




\section{Conclusions}

This was a preliminary study in order to obtain practical information about the formation and characteristics of use-wear features on basalt artefacts, and the types of alteration on the surface of basalt flakes that can be used to distinguish trampling or other PDSM from usewear traces on basalt. Although preliminary and quantitatively not reinforced, the results of the study have allowed us to establish some qualitative criteria about types of alteration on basalt. Of course our results are not definitive and may change or be updated with new data that we hope to get from ongoing experiments, as well as new studies and experiments that will take into account the results of the current study. Our observations are as follows:

- For both use and PDSM related experiments with basalt, experimental time should be longer and, correspondingly, actions more intensive than in case of other rocks (e.g., flint, obsidian, quartz) as the tough character of basalt impedes damage in short-term use, or alteration is so minimal that it is difficult to see even microscopically.

- The sequential character of these experiments is very important as it allows us to follow changes occurring to each piece over time, and provides the opportunity to register any macro- and microscopic change. Because of the characteristics of basalt, it is important to register periodically the gradual changes and types of alteration.

- Macroscopically, changes in basalt may be difficult to see, apart from the formation of a whitish patina and slight edge fractures.

- The combined use of both optical and electronic microscopes is beneficial and complementary. Features such as edge micro-flaking, micro-fractures, and edge rounding can be recorded effectively using the low magnifications of optical microscopes (x50-x100), while specific use-wear features such as polish and striations require higher magnifications of the SEM (x250 - x2000).

- The location of alteration and its development on particular areas of the piece may be effective in recognising and studying use-wear traces on archaeological basalt pieces, although this hypothesis needs to be confirmed with further experiments of longer duration, and by using a combination of use-wear and PDSM experiments on the same flake.

- As with many other rocks, edge rounding, polish, abrasion, plastic deformation and linear features or striations were the most evident types of alteration on basalt flakes, although occurring at different times and different types of use. However, the orientation and distribution of these alterations may be an important indicator to differentiate use-wear from post-depositional alterations on basalt artefacts.

- Recognition of use-wear traces on archaeological basalt artefacts is difficult. Nevertheless, based on our experimental results, it is possible to distinguish some specific features that may be of use. Our results suggest that bears (Ursus Spelaeus), although an important agent of PDSM of Azokh Cave assemblages, probably were not the only agent responsible for alterations evident on the basalt flakes studied here. Although experimental work is crucial to aid an understanding of the nature of usewear and PDSM alterations, we must rigorously consider the range of other potential agents which may have affected archaeological artefacts in their specific contexts.

The study, presented here, of experimental work on use-wear and PDSM on basalt flakes is valuable in indicating the likely characteristics that may result, and in demonstrating, too, the continuing problems which we must address. The way forward is to expand the experimental study and complement it with new data from other raw materials. Perhaps, then, we may be able to determine, more clearly, features that separate use-wear from PDSM on basalt artefacts. 


\section{Acknowledgments}

We thank the members of Boumort and Cabarceno Natural parks for facilitating the experimental processes. To O. Crandell, A. Rodríguez and anonymous reviewers, we are grateful for their useful comments and suggestions that helped to improve and to better focus the initial idea of this study. L. Asryan is grateful to a grant from Wenner-Gren Foundation (WIF-212). This work has been developed within the general framework of the Spanish MICINN project CGL2012-38434-C03-03 and the Catalan AGAUR project 2009SGR-188.

\section{References}

Araho, N., Torrence, R. \& White, J.P. 2002, Valuable and useful: Mid-Holocene stemmed obsidian artefacts from West New Britain, Papua New Guinea. Proceedings of the Prehistoric Society, 68: 61-81. doi:10.1017/S0079497X00001444

Asryan, L., Moloney, N. \& Ollé, A. (in press), Lithic assemblages recovered from Azokh 1 (Chapter 4). In: Azokh Cave and the Transcaucasian Corridor (Fernández-Jalvo, Y., Andrews, P., King, T. \& Yepiskoposyan, L., Eds.) Vertebrate Paleobiology and Paleoanthropology Series, Springer, Dordrecht.

Barton, H., Torrence, R. \& Fullagar, R.L.K. 1998, Clues to stone tool function re-examined: Comparing starch grain frequences on used and unused obsidian artefacts. Journal of Archaeological Science, 25(12): 1231-1238. doi:10.1006/jasc.1998.0300

Baryshnikov, G. \& Hoffecker, J.F. 1994, Mousterian hunters of the NW Caucasus:

Preliminary results of recent investigations. Journal of Field Archaeology, 21: 1-14. doi: $10.2307 / 530241$

Beyin, A. 2010, Use-wear analysis of obsidian artefacts from Later Stone Age shell midden sites on the Red Sea Coast of Eritrea, with experimental results. Journal of Archaeological Science, 37: 1542 - 1556. doi:10.1016/j.jas.2010.01.015

Borel, A., Ollé, A., Vergès, J.M. \& Sala, R. (in press), Scanning Electron and Optical Light Microscopy: two complementary approaches for the understanding and interpretation of usewear and residues on stone tools. Journal of Archaeological Science. doi: $10.1016 /$ j.jas.2013.06.031

Burroni, D., Donahue, R.E., Pollard, A.M. \& Mussi, M. 2002, The surface alteration of flint artefacts as a record of environmental processes. Journal of Archaeological Science, 29: 1277-1287. doi:10.1006/jasc.2001.0771

Clemente, I. \& Gibaja, J.F. 2009, Formation of use-wear traces in non-flint rocks: the case of quartzite and rhyolite. Differences and similiraties. In: Non-flint Raw Material Use in Prehistory. Old prejudices and new directions. UISPP - Proceedings of the World Congress (Lisbon, 4-9 September 2006), vol 11. B.A.R. International Series Vol. 1939 (Sternke, F., Eigeland, L. \& Costa, L.-J., Eds.), Archaeopress, Oxford: p. 93-98.

Deunert, B. 1995, A fundamental basalt flake analysis. Based on experimentally-produced and used flakes as well as the prehistoric Waikalua material. Vol. 614. B.A.R. Inernational Series. Tempus Reparatum, Oxford.

Eren, M.I., Boehm, A.R., Morgan, B.M., Andreson, R. \& Andrews, B. 2011, Flaked stone taphonomy: A controlled experimental study of the effects of sediment consolidation on flake edge morphology. Journal of Taphonomy, 9(3): 201-217.

URL: http://www.journaltaphonomy.com/JT-articles/2011/issue3/jt-119TRIS.pdf 
Fernández-Jalvo, Y. \& Andrews, P. 2003, Experimenta effects of water abrasion on bone fragments. Journal of Taphonomy, 1: 147-163.

URL: http://www.anthro.utah.edu/PDFs/fernandez-jalvo.pdf

Fernández-Jalvo, Y., King, T., Andrews, P., Yepiskoposyan, L., Moloney, N., Murray, J., Domínguez-Alonso, P., Asryan, L., Ditchfield, P., Made, J.v.d., Torres, T., Sevilla, P., Nieto Díaz, M., Cáceres, I., Allué, E., Marín Monfort, M.D. \& Sanz Martín, T. 2010, The Azokh Cave complex: Middle Pleistocene to Holocene human occupation in the Caucasus. Journal of Human Evolution, 58: 103-109. doi:10.1016/j.jhevol.2009.07.005

Flenniken, J.J. \& Haggarty, J. 1979, Trampling as an agency in the formation of edge damage: an experiment in lithic technology. Northwest Anthropological Research Notes, 13: 208-214.

Van Gijn, A. 1990, The wear and tear of flint: Principles of functional analysis applied to Dutch Neolithic assemblages. Vol. 22. Analecta Praehistorica Leidensia. University of Leiden, Leiden, 181 p. URL: https://easy.dans.knaw.nl/ui/datasets/id/easydataset:33488/tab/2

Golovanova, L., Hoffecker, J., Kharitonov, V. \& Romanova, G. 1999, Mezmaiskaya cave: A Neanderthal Occupation in the Northern Caucasus. Current Anthropology, 40: 77-86. doi: $10.1086 / 515805$

Grace, R. 1989, Interpreting the function of stone tools. The quantification and computerisation of microwear analysis. B.A.R. International Series Vol. 474. British Archaeological Reports, Oxford, 255 p.

Hayden, B., (Ed), 1979, Lithic use-wear analysis, Studies in Archaeology. Academic Press, New York, 205 p.

Hong, M. \& Kononenko, N. 2005, Obsidian tools and their use excavated from the Hopyeong-dong Upper Paleolithic Site, Korea. Journal of the Korean Paleolithic Society, 12: 1-30.

Hurcombe, L.M. 1992, Use-wear analysis and obsidian: Theory, experiments and results. Sheffield Archaeological Monographs Vol. 4. J.R. Collis, Sheffield, 226 p.

Kamminga, J. 1979, The Nature of Use-Polish and Abrasive Smoothing on Stone Tools. In: Lithic Use-Wear Analysis (Hayden, B., Ed.) Studies in Archaeology, Academic Press, New York: p. 143-157.

Keeley, L.H. 1980, Experimental Determination of Stone Tools Uses: A Microwear Analysis. Prehistoric archeology and ecology. The University of Chicago Press, Chicago, 212 p.

Knutsson, K. 1986, SEM-Analysis of Wear Features on Experimental Quartz Tools. Early Man News, 9/10/11: 35-46.

Kononenko, N. 2007, The contribution of use-wear/residue studies of obsidian artefacts for understanding changes in settlement and subsistence patterns in West New Britain, Papua New Guinea. Bulletin of the Indo-Pacific Prehistory Association, 27: 135-143.

Kononenko, N. 2011, Experimental and archaeological studies of use-wear and residues on obsidian artefacts from Papua New Guinea. Technical Reports of the Australian Museum, Online, 21: p. 1-244; Accessed: 01 March 2014.

URL: http://australianmuseum.net.au/journal/Kononenko-2010-Tech-Rep-Aust-Mus$\underline{\text { Online-21-1244 }}$ 
Kuhn, S.L., Arsebük, G. \& Howell, F.C. 1996, The Middle Pleistocene Lithic Assemblages from Yarimburgaz Cave, Turkey. Paléorient, 2: 31-49. doi:10.3406/paleo.1996.4625

Levi-Sala, I. 1986, Use-wear and post-depositional surface modification: a word of caution. Journal of Archaeological Science, 13: 229-244. doi:10.1016/0305-4403(86)90061-0

van der Made, J., Torres, T., Ortiz, J.E., Moreno-Pérez, L. \& Fernández-Jalvo, Y. (in press), The new material of large mammals from Azokh and comments on the older collections (Chapter 6). In: Azokh Cave and the Transcaucasian Corridor (Fernández-Jalvo, Y., Andrews, P., King, T. \& Yepiskoposyan, L., Eds.) Vertebrate Paleobiology and Paleoanthropology, Springer, Dordrecht.

Marín-Monfort, M.D., Cáceres, I., Andrews, P. \& Fernández-Jalvo, Y. (in press), Taphonomy and site formation of Azokh 1 (Chapter 10). In: Azokh Cave and the Transcaucasian Corridor (Fernández-Jalvo, Y., Andrews, P., King, T. \& Yepiskoposyan, L., Eds.) Vertebrate Paleobiology and Paleoanthropology Series, Springer, Dordrecht.

McBrearty, S., Bishop, L., Plummer, T., Dewar, R. \& Conard, N.J. 1998, Tools Underfoot: Human trampling as an agent of lithic artifact edge modification. American Antiquity, 63(1): 108-129. doi: $10.2307 / 2694779$

Moncel, M.-H. \& Rivals, F. 2011, On the question of short-term Neanderthal site occupations Payre, France (MIS 8 - 7), and Taubach/Weimar, Germany (MIS 5). Journal of Anthropological Research, 67: 47-75.

Murray, J., Domínguez-Alonso, P., Fernández-Jalvo, Y., King, T., Lynch, E.P., Andrews, P., Yepiskoposyan, L., Moloney, N., Cáceres, I., Allué, E., Asryan, L., Ditchfield, P. \& Williams, D.M. 2010, Pleistocene to Holocene stratigraphy of Azokh 1 Cave, Lesser Caucasus. Irish Journal of Earth Science, 28: 75-91. doi:10.3318/IJES.2010.28.75

Murray, J., Lynch, E.P., Domínguez-Alonso, P. \& Barham, M. (in press), Stratigraphy and Sedimentology of Azokh Caves (Chapter 2). In: Azokh Cave and the Transcaucasian Corridor (Fernández-Jalvo, Y., Andrews, P., King, T. \& Yepiskoposyan, L., Eds.) Vertebrate Paleobiology and Paleoanthropology Series, Springer, Dordrecht.

Newcomer, M.E. 1976, Spontaneous retouch. Staringia, 3: 62-64.

Odell, G.H. 1977, The application of microwear analysis to the lithic component of an entire prehistoric settelment: methods, problems and functional reconstructions. $\mathrm{Ph}$. D. thesis at the Department of Anthropology, University of Harvard, Cambridge, Massachusetts.

Odell, G.H. 1981, The Mechanics of Use-breakage of Stone Tools: Some Testable Hypotheses. Journal of Field Archaeology, 8(2): 197-209. doi: $10.1179 / 009346981791505120$

Ollé, A. 2003, Variabilitat i patrons funcionals en els sistemes tècnics de Mode 2. Anàlisi de les deformacions d'ús en els conjunts lítics del Riparo Esterno de Grotta Paglicci (Rignano Garganico, Foggia), Áridos (Arganda, Madrid) i Galería-TN (Sierra de Atapuerca, Burgos). Ph.D. thesis at the Dept. d'Història i Geografia, Universitat Rovira i Virgili, Tarragona, 589 p. (in Catalan) ("Variability and functional patterns in the mode 2 technical systems. Use-wear analysis of the lithic assemblages from Riparo Esterno de Crotta Paglicci (Rignano Garganico, Foggia), Áridos (Arganda, Madrid) and Galería-TN (Sierra de Atapuerca, Burgos") URL: http://tdx.cat/handle/10803/8603 
Ollé, A. \& Vergès, J.M. 2008, SEM functional analysis and the mechanism of microwear formation. In: 'Prehistoric Technology' 40 years later: Functional Studies and the Russian Legacy. Proceedings of the International Congress Verona (Italy), 20-23 April 2005 Vol. 1783 (Longo, L. \& Skakun, N., Eds.) B.A.R. International Series, Archaeopress, Oxford: p. 39-49.

Ollé, A. \& Vergès, J.M. (in press), The use of sequential experiments and SEM in documenting stone tool microwear. Journal of Archaeological Science. doi: $10.1016 /$ j.jas.2013.10.028

Plisson, H. 1982, Une analyse fonctionnelle des outillages basaltiques. In: Tailler ! Pour quoi faire. Recent Progress in Microwear Studies (Cahen, D., Ed.), Musée Royal de l'Afrique Centrale, Tervuren: p. 241-244. (in French) ("A functional analysis of basalt tools")

Quiles, J., Moigne, A.-M. \& Pois, V. 2004, Les couches à ossements d'Ursidae de la Cune de l'Arago. Revue de Paléobiologie, 23(2): 821-843. (in French) ("The units with Ursidae remains of Arago Cave")

Richards, T.H. 1988, Microwear Patterns on Experimental Basalt Tools. B.A.R. International Series Vol. S460. British Archaeological Reports, Oxford, 283 p.

Rodríguez Rodríguez, A.C. 1998, Primeras experiencias de análisis funcional en los instrumentos de basalto tallado de Canarias. El ejemplo del material prehistórico de la isla de La Palma. Vegueta, 3: 29-46. (in Spanish) ("First experiences of functional analysis of basalt knapped artefacts in Canarias. The example of prehistoric material of La Palma island")

URL: http://revistavegueta.ulpgc.es/ojs/index.php/revistavegueta/article/view/143

Stiner, M.C. 1999, Cave bear ecology and interactions with Pleistocene humans. Ursus, 11: 41-58.

URL: http://www.bearbiology.com/fileadmin/tpl/Downloads/URSUS/Vol_11/Stiner_V ol_11.pdf

Stiner, M.C., Arsebük, G. \& Howell, F.C. 1996, Cave Bears and Palaeolithic Artefacts in Yarimburgaz Cave, Turkey: Dissecting a Palimpsest. Geoarchaeology: an International Journal, 11: 279-327. doi:10.1002/(SICI)1520-6548(199607)11:4<279::AIDGEA1>3.0.CO;2-Z

Sussman, C. 1988, Aspects of microwear as applied to quartz. In: Industries lithiques. Tracéologie et Technologie Vol. 411 (ii) (Beyries, S., Ed.) B.A.R. International Series, John and Erika Hedges Ltd., Oxford: p. 3-28.

Thiébaut, C. 2007, Les pièces encochées au Paléolithique moyen et les pseudo-outils: peut-on les distinguer? In: Un siècle de construction du discours scientifique en Préhistoire. Actes du Congrès Préhistorique de France, XXVIe session, 21 - 25 septembre 2004, Avignon Vol. 3 (Evin, J., Ed.), Avignon: p. 201-216. (in French) ("Middle Palaeolithic notches and pseudo-tools : Can they be distinguished?")

Toll, H.W. 1978, Quartzite lithic material in archaeology: qualities and quandaries with special reference to use-wear. Plains Anthropologist, 23: 47-68. Stable URL: http://www.jstor.org/stable/25667443

Tringham, R., Cooper, G., Odell, G.H., Voytek, B. \& Whitman, A. 1974, Experimentation in the formation of edge-damage: a new approach to lithic analysis. Journal of Field Archaeology, 1(1-2): 171-196. doi:10.1179/jfa.1974.1.1-2.171 
Vallin, L., Caspar, J.-P., Guillemet, G., Masson, B. \& Ozouf, J.-C. 2013, Altérations des artefacts préhistoriques en silex par les processus périglaciaires: Présentation des expériences conduites au centre de gómorphologie du CNRS de Caen. Quaternaire, 24(3): 259-266. (in French) ("Alterations of prehistoric lithic artefacts of flint by periglacial processes: Presentation of experiments carried out in the centre of geomorphology of CNRS in Caen") URL: http://quaternaire.revues.org/6658

Vallin, L., Masson, B. \& Caspar, J.P. 2001, Taphonomy at Hermies, France: a mousterian knapping site in a Loessic context. Journal of Field Archaeology, 28(3-4): 419-436. doi: $\underline{10.1179 / j f a .2001 .28 .3-4.419 ~}$

Vaquero, M. 2011, New perspectives on recycling of lithic resources using refitting and spatial data. Quartär, 58: 113-130. doi:10.7485/QU58_06

Vaughan, P.C. 1985, Use-wear analysis of flaked stone tools. University of Arizona Press, 204 p. URL: http://books.google.com/books?id=aicSAQAAIAAJ

Vergès, J.M. 2003, Caracterització dels models d'instrumental lític del mode 1 a partir de les dades de l'anàlisi funcional dels conjunts litotècnics d'Ä̈n Hanech i El-Kherba (Algèria), Monte Poggiolo i Isernia la Pineta (Itàlia). Ph.D. thesis at the Dept. d'Història i Geografia, Universitat Rovira i Virgili, Tarragona. (in Catalan) ("Characterisation of Mode 1lithic artefacts models based on the results of functional analysis of the lithic assemblages of Aïn Hanech and El-Kherba (Algeria), Monte Poggiolo and Isernia La Pineta (Italy)") 